\section{Muitas gramáticas, muitas normas: por que ensinar língua padrão?}

\author{
Many grammars, many \\ norma: why teach standart \\ language?
}

Marcelo Moraes CAETANO (UERJ) marcelomcaetano@gmail.com
CAETANO, Marcelo Moraes. Muitas gramáticas, muitas normas: por que ensinar língua padrão? Entrepalavras, Fortaleza, v. 6, n. 2, p. 292-306, jul./dez. 2016.

Resumo: A linguagem, com a pluralidade que seu conteúdo encerra, se realiza na expressão de uma língua concreta, atravessada pela interdiscursividade, patenteada na multiplicidade de textos, de que tratam autores como Charaudeau e Maingueneau (2011). Toda língua, por ser imanente a pessoas com histórias e culturas diversas, apresenta extensa diversidade discursiva, refletida nos domínios ou comunidades diferentes que dela lancem mão. Todos esses diversos domínios, no entanto, apresentam normas para que seus falantes se compreendam. Essas normas, quando agrupadas em conjuntos, podem ser consideradas como gramáticas que perpassam e descrevem as variantes da língua em questão, o que ocasiona uma polissemia inerente aos conceitos de "gramática" e de "norma". Cabe à escola a perspectiva de, dialeticamente às variantes havidas por diversos fatores, apresentar ao aluno a variante da língua chamada padrão, porque tal variante é adequada a certos contextos situacionais e, por isso, seu conhecimento permite o acesso pleno à cidadania, como mostra Azeredo (2008). Procuro, neste artigo, explicitar essa afirmação, bem como esboçar meios para que haja êxito no ensino da gramática 
da norma padrão, alicerçado num conjunto de práticas que envolve a prescrição (evidenciada por estudiosos como BECHARA, 1990), a subjetividade (encarecida por linguistas como BENVENISTE, 1998) e a alteridade (presente nos trabalhos de FIORIN, 2006; NEVES, 2000 e ANTUNES, 2003).

Palavras-chave: Normas. Gramáticas. Norma-padrão.

Abstract: Language, with its plural contents, takes place in the expression of a specific speech, crossed by interdiscursivity, patented in the multiplicity of texts, as Charaudeau and Maingueneau (2011) taught. Every language, being immanent to people with different histories and cultures, has an extensive discursive diversity, reflected in the different domains or communities that take hold of it. All these various domains, however, provide patterns for their speakers to understand each other. These patterns, when grouped in sets, can be considered as grammars that describe the variants of a language, which causes a polysemy inherent to the concepts of "grammar" and "pattern". It is up to the school, in a dialectical perspective involving variants born in several factors, present to the student the standard variant, because this variant is suitable to certain situational contexts and, therefore, their knowledge allows full access to citizenship, as shown by Azeredo (2008). I try in this paper to explain this statement, as well as outline ways to generate a successful standardgrammar teaching, based on a set of practices involving prescription (evidenced by scholars as BECHARA, 1990), subjectivity (taken by linguists as BENVENISTE, 1998) and otherness (presented in the works of FIORIN, 2006; NEVES, 2000 and ANTUNES, 2003).

Keywords: Patterns. Grammars. Standard-grammar.

\section{Introdução}

Para lidarmos com ensino de Gramática Normativa, é preciso antes de tudo atravessar-se o que Hugo Schuchardt (1992), um dos pais da Filologia, celebremente alertou representar para o cientista o mesmo perigo que o nevoeiro acarreta para o comandante de um navio: a imprecisão e a despreocupação com o rigor técnico que deveria ser emprestado aos termos com que se quer operar. Assim, para começarmos, os próprios conceitos de "norma" e de "gramática", básicos à expressão deste texto, apresentam polissemias e imprecisões que dificultam - ou impossibilitam - uma discussão franca entre alunos e professores (e entre professores uns com os outros) que venha a render resultados úteis e merecedores de debate real, ou seja, aquele em que todos saiam ganhando, sobretudo o aluno.

Agrava essa circunstância o fato de que, frequentemente, supostos opositores da discussão franca a que alude se aferram não aos conceitos em si mesmos (e à problemática verdadeira de suas polissemias), mas, sim, aos estereótipos quase sempre já ultrapassados desses conceitos ou a estigmas que fizeram parte de sua existência num passado muitas vezes longínquo. 
v. 6 (2) 292-306 $\mathrm{jul} / \mathrm{dez}$ 2016

Trato disso num artigo recente, que publiquei em coautoria com Alexandre Chini, no Instituto dos Magistrados do Brasil, que peço licença para citar:

[...] em ciências humanas em geral - Linguística inclusa -, o que parece permanecer por vezes é um preconceito não ao conceito em si, mas aos estigmas que lhes foram cravados nos anos oitocentos, cujo objetivo [...] era, naquele momento, promover uma fronteira-separação inequívoca entre as disciplinas, um limite acima do bem e do mal, como que para fornecer-lhes chancela de "necessidade" de existência e... sobrevivência. (CAETANO; CHINI, 2016, p. 3-4, grifei)

"Norma", por exemplo, a par de trazer consigo a polissemia natural, problemática verdadeira que deve ser encarada com seriedade por estudiosos de linguagem, traz consigo uma espécie de ferrugem ou estigma que já não é mais considerada por especialistas comprometidos com a honestidade acadêmica. Atacam-na, por exemplo, pesquisadores que a inquinam de "elitista", "não científica", "arbitrária", "irrealista" - sem perceberem que todos esses predicados dizem respeito, no máximo, a um único tipo específico de "norma" e, mais grave, havido num momento muito específico do decurso dos estudos de linguagem, que definitivamente não é o momento contemporâneo.

Tentemos, portanto, sair do nevoeiro epistêmico de que Schuchardt (1992) nos preveniu.

Há duas possibilidades básicas que podem estar comprometidas ao discernimento do conceito de "norma", que parte, ab ovo, de uma noção cultural, antropológica, social.

"Norma" pode dizer respeito ao que é exercido pela maioria das pessoas, sendo "normal" qualquer comportamento - linguístico ou não - cujo lastro seja de caráter quantitativo. Não é "normal" que homens usem saias no Brasil. Isso tão somente, segundo esta primeira perspectiva, porque a maioria dos homens no citado país não o fazem. É "normal", entretanto, que homens usem uma vestimenta idêntica à saia na Escócia, porque aí há uma maioria de homens que, em determinadas circunstâncias, usam a roupa mencionada. Como foi dito, trata-se apenas de uma avaliação quantitativa.

Por outro lado, "norma" pode provir de um conceito que, agora de caráter qualitativo, permeia juízos de valor, devendo aconselhar (prescrever) comportamentos adequados a quaisquer comunidades, domínios e grupos para que, entre seus membros, haja organização e conhecimento prévio de limites, reconhecimentos e respeitos recíprocos. 
Prescreve-se, por exemplo, que, num país como o Brasil, um chefe de Estado não se apresente em solenidade pública sem camisa, algo que é perfeitamente adequado, entretanto, em várias outras nações.

$\mathrm{Na}$ verdade, parece-nos que, de certa forma, o conceito de "norma", quando aplicado às gramáticas (não falo da Gramática Escolar ou Normativo-padrão apenas, como veremos) abarca ambas as noções acima esboçadas, sem que uma contradiga ou menoscabe a outra. Norma, portanto, quando aplicada aos estudos gramaticológicos, advirá: 1) da equação entre o que é mais usual entre os falantes escreventes de uma língua (aspecto quantitativo), sem o que língua alguma seria sequer compreendida; 2) no caso de uma Gramática de Norma-padrão (embora nem mesmo exclusivamente nesta, como mostrei), de um conjunto de prescrições que atestam as adequações culturais linguísticas de um povo que domine aquela língua e saiba adequá-la a situações discursivas diversas (aspecto qualitativo).

Por isso mesmo, este texto imbui-se da consciência de que se fala em uma (apenas uma) das normas da gramática, que é a Padrão, sabedor de que, como esboçamos, em gramática e em língua, tudo é norma, tudo é prescrição de comportamentos, sem cuja existência a língua mesma não poderia existir, porque lhe faltariam os elementos necessários à comunicabilidade, à alteridade, à transmissão de pensamentos por via verbal, ao ajuste do conteúdo à sua expressão adequada a contexto e situação, usando expressões consagradas de Hjelmslev (2001), Martinet (1973), Bar-Hillel (1973) e Malinowski (1970).

O primeiríssimo conceito de "gramática" congrega, antes de qualquer outra função, a de estabelecer os meios com os quais os falantes e escreventes de quaisquer - quaisquer - comunidades e domínios discursivos poderão compreender-se reciprocamente. Estabelecem-se as regras com as quais frases fazem sentido numa língua, que não é um aglomerado desconexo ou aleatório de palavras.

Desse modo é que, por fim, para dar cabo a este brevíssimo exórdio sobre a problemática real da polissemia dos conceitos de "norma" e "gramática" em geral, para em seguida aprofundar-me na necessidade do ensino de uma gramática de uma norma específica (agora sim a Norma-padrão), peço licença para citar-me mais uma vez:

A descrição completa de uma língua, com efeito - e na verdade -, parece nunca opor-se verdadeiramente à prescrição, uma vez que, como veremos, a língua, "sistema de sistemas" (cf. Saussure), virtualidade, "gramática universal" ou input inicial (cf. Chomsky), até chegar ao seu estágio estável (idem), só 
v. 6 (2) 292-306 jul/dez 2016

\section{Ensino de Norma-Padrão e acesso pleno à cidadania}

\section{Abro este subitem com nova citação de José Carlos Azeredo:}

Toda a sociedade sabe, e os políticos gostam de repetir nas promessas de campanha. Que um país só cresce de fato quando melhora a qualidade da educação de seu povo. É por meio dela

Cidadania é conceito que pode ser definido como a relação recíproca entre o Estado e o indivíduo. Bakhtin enfatizou as políticas de ensino como ferramentas indispensáveis à sua consecução. Paulo Freire também o fez.

Uma das necessidades do desenvolvimento das competências intelectivas e emotivas da Gramática Padrão de uma língua reside precisamente no fato de que esse desenvolvimento é sine qua non ao acesso à cidadania plena. Assim, o ensino desta Gramática específica deverá ser levado a termo e tornado possível por meios que levem o aluno, dialeticamente, a pensar o mundo com o auxílio inevitável das linguagens coloquial e padrão, concretizadas na língua.

De quando em vez, se acende um debate sobre a suposta "opressão" que o ensino da Gramática Normativa geraria nos falantes de uma determinada língua. Evanildo Bechara (1990) elaborou obra bastante conhecida a esse respeito: "Ensino da Gramática: Opressão? Liberdade?"

A Gramática Padrão não passa de uma das formas de expressão 
dentro de uma língua, mas está longe de ser a única ou, em muitos casos, mesmo a melhor. No entanto, como foi dito, é antidemocrático e demagógico levar as pessoas que não tiveram acesso àquela Gramática a continuar nesse estado, enquanto a classe dos que puderam acedê-la se diferenciariam exatamente por esse acesso.

Os atuais estudos sobre linguagem e língua, alicerçados em fontes científicas da Antropologia, da Linguística, da Sociologia, da Etnologia, das Sociolinguísticas, levam em consideração a perspectiva êmica, e não apenas ética. Isto é, trabalha-se com a visão a partir da perspectiva do povo estudado, e não levando como referencial único a ética dos estratos mais favorecidos socioeconomicamente. No entanto, numa cidade (e, portanto, torno a falar em cidadania) e num mundo que cada vez mais necessita de padrões comunicativos que propiciem a comunicabilidade, desconsiderar o ensino da Gramática Padrão constitui "algo como 'deixem a língua culta com as elites; deem aos plebeus a sua língua que só sabe expressar-se de uma forma, onde quer que estejam'"). (CAETANO, 2012, p. 15)

Aliás, devo dizer que o Brasil é o único país do mundo que vocifera com tanta ferocidade (e falta de fundamentos) contra a Gramática Normativa de sua língua. Nenhum outro país considera a sua Gramática um conglomerado de arbitrariedades e algemas, porque sabem que todas as Gramáticas são escritas mediante pesquisa de séculos de literatura naquela língua em questão. Ademais, a Gramática, sendo filosófica e reflexiva, como é, alarga o pensamento daqueles que a procuram conhecer e estudar, pois "a linguagem é a casa do ser", como disse Heiddeger, e Pessoa dizia que "vemos o mundo com os olhos da nossa língua", e, dessa forma, uma pessoa que possua poucos ou parcimoniosos recursos expressivos e comunicativos dentro de sua língua há de ter um pensamento igualmente parcimonioso.

Tudo no mundo tem suas Gramáticas: a linguagem computacional tem sintaxe, morfologia, léxico, semântica; as relações interpessoais idem. A Gramática Normativa, se não é o fator exclusivo de ensino de leitura da Gramática do mundo (e realmente não o é), ao menos é um elemento extremamente útil para esse fim. Creio que seja por essa razão que os demais países do mundo - à exceção do Brasil - RESPEITEM as suas Gramáticas, em vez de apedrejá-las, e, pior ainda, com argumentos falsos e conceitos para lá de ultrapassados, praticamente jurássicos... e deturpados, mal lidos, simplificados a um sem-número de abjetas formas de preconceito disfarçadas sob a "pele de cordeiro" da falaciosa "democracia". Demagogia e segregação seriam palavras mais exatas. (CAETANO, 2012, I-VI)

Digo eu constantemente, como exemplo que me parece suficiente, 
v. 6 (2)

292-306

jul/dez

2016

que uma criança já em tenra idade é capaz de discernir noções de uso adequado e inadequado de sua língua. Ela não dirá um palavrão em certos locais, a menos que queira chocar com seu uso, caso em que, também, estará dando conscientemente guarida ao uso do que lhe parece adequado, e não inadequado, fazer naquele momento: chocar.

Assim, a discussão - mas no momento adequado à maturidade do aluno - a respeito dos limites entre normatividade e coloquialidade é salutar e necessária. Mas isso não implica que se deva retirar o ensino da normatividade, substituindo-o pela exclusiva manutenção da competência linguística coloquial de que o aluno já dispõe, e de que continuará dispondo, antes e depois de sua vida escolar, de que o letramento, no sentido de permissão de acesso às esferas comunicativas que o aluno escolher aceder, deve fazer parte ativa.

\section{Ensino sem preconceito e sem traumas: algumas palavras}

Desse modo, vejo que é possível ensinar a Gramática Normativa, desde que o professor conheça a sua necessidade e a sua utilidade (mas não necessariamente a curto prazo) em promover no aluno a iniciação e o desenvolvimento do senso crítico e o acesso pleno à cidadania: "[...] desenvolver a leitura e a escrita, habilidades sem as quais a educação escolar em geral é impossível" (AZEREDO, 2008, p. 31, grifei). Possuindo esses parâmetros com clareza, o professor perceberá onde as possibilidades do ensino se instauram, e conseguirá não enfatizar nem pontos demasiado abstratos ou teóricos para determinados níveis de maturidade discente, nem obscurecer ou relegar outros que, no futuro (breve ou longínquo), ou mesmo no presente, serão de importância capital à vida escolar e social de seu aluno.

Considero que haja basicamente três pontos sobre os quais o ensino de Gramática Padrão se consolidará de modo eficiente: 1) a alteridade, 2) a textualidade, 3) as etapas do ensino.

Ora, apesar de as gramáticas filosóficas (que em suas versões atuais podem aparecer com subtítulos como "compreensivas", "críticas", "reflexivas" etc.) considerarem a língua como objeto de raciocínio e pensamento, tão preponderantemente quanto o são como objeto de comunicação de ideias e conceitos, percebo que ambos os potenciais do ensino da Gramática devam ser levados à sala de aula. A questão da comunicação, entretanto, parece-me dever ser, sempre, enfatizada. 
Explicitando, quero dizer que a Gramática Padrão, mesmo em sua metalinguagem, desde que exposta num arrazoado lúcido de exposição e explicitação de nomenclaturas - que não deveriam ser vítimas de preconceitos para determinadas audiências discentes com grau de maturidade cognitiva à altura das abstrações necessárias -, possui o condão de desenvolver no aluno o pensamento abstrato, filosófico, científico, acadêmico.

Já os aspectos relativos à eficiência da Gramática como instrumento de comunicação, isto é, como fator que leva em conta a ampliação da competência de alteridade ou, como alguns autores chamam, outredade, devem ser sempre encarecidos. A eficiência completa do ensino de Gramática, incluindo-se a da Norma Padrão, sempre trabalhada em dialética com as demais Gramáticas discursivas trazidas pela realidade coloquial do aluno - que tampouco deve ser vítima de preconceitos, pois a prática pedagógica exploratória parte daí -, se concretizará e logrará êxito se for baseada, antes do mais, na discursividade, ou, repita-se, na questão da comunicação ou alteridade.

Assim, trago à luz dois enunciados propostos por Émile Benveniste. O primeiro, enfatiza o sujeito; o segundo, o interlocutor:

[...] a capacidade do locutor para se propor como "sujeito". Essa proposição como sujeito tem como condição a linguagem. É na linguagem e pela linguagem que o homem se constitui como sujeito; porque só a linguagem fundamentada na realidade, na sua realidade, que é a do ser, o conceito de ego, se alcança a comunicação, ainda que interna. (BENVENISTE, 1998, p. 288)

[...] o que caracteriza a enunciação é a acentuação da relação discursiva com o parceiro, seja este real ou imaginário, individual ou coletivo. (BENVENISTE, 1998, p. 87)

Percebe-se, pela análise dos fragmentos acima, que o ensino da língua materna deva, antes, fomentar, como deixei explicitado, o desenvolvimento do que Benveniste chamaria de subjetividade, ou, indo-se a Freud, o que ele evoca como "o conceito de ego". No entanto, o mesmo Benveniste procurará, em seguida, articular esse desenvolvimento, indispensável, como vimos, à presença do "parceiro", querendo dizer, com isso, que a linguagem, concretizada na língua e registrada na sua gramática, servirá, no fundo, como instrumento de comunicação, com interlocutor "real ou imaginário, individual ou coletivo".

Como o ser humano é inconcebível fora das relações que o ligam 
v. $6(2)$

292-306

$\mathrm{jul} / \mathrm{dez}$

2016

ao outro, parafraseando Bakhtin (cf. FIORIN, 2006), a alteridade deve ser estimulada nos estudos gramaticais em sala de aula, a fim de que todos os seus conceitos, mesmo os mais abstratos e filosóficos, sejam percebidos pelo aluno como uma ferramenta efetiva de que ele poderá lançar mão em sua vida.

Dessa forma, o que Fiorin procura distinguir como interdiscursividade (FIORIN, 2006), calcado nos estudos da Análise do Discurso (CHARAUDEAU; MAINGUENEAU, 2008), baseia-se, justamente, na competência que o sujeito possui (ou desenvolve) em observar, no seu discurso e na relação desse discurso com o discurso do outro, um teor de significações subjacente, que não seria claro a quem não tivesse essa competência interdiscursiva desenvolvida.

Para isso, é preciso levar em consideração que o ethos discursivo - concebido aqui como "a imagem de si que o locutor constrói em seu discurso para exercer uma influência sobre seu alocutário" (CHARAUDEAU; MAINGUENEAU, 2008, p. 220) - varia de tal modo, que as relações entre dois ou mais ethi precisam ser sempre evocadas à discussão nos ensinos de Gramática.

O ethos de um discurso resulta de uma interação de diversos fatores: ethos pré-discursivo, ethos discursivo (ethos mostrado), mas também de fragmentos do texto em que o enunciador evoca sua própria enunciação (ethos dito) [...]. (MAINGUENEAU, 2006, p. 16)

Como vimos, a impossibilidade de o ser humano viver alheio a uma comunidade, e a impossibilidade, ainda, de que a interação se dê sem a presença da linguagem/língua, tudo isso torna imprescindível o ensino contextualizado (com + texto) da gramática daquela língua que, sempre, será mostrada como um dos meios de vida e convívio do aluno.

A heterogeneidade das relações sociais, complexas por natureza, gera um entrecruzamento de vozes que, na linguagem (consubstanciada na língua, contextualizada em situações e contextos específicos de condições de produção), gera o que se conhece como "polifonia", que se imiscui, por fim, na concretização do "dialogismo": "[...] A polifonia não se estabelece nos enunciados ou pontos de vista, mas na existência de vários locutores - reais ou representados". (CHARAUDEAU; MAINGUENEAU, 2008, p. 388). 
determinados. A descentralização do sujeito ocorre, então, num processo de tensão entre o eu e o tu, e o dialogismo bakhtiniano é entendido como interação entre locutor e destinatário (BRAIT, 1999, p. 87)

Dessa maneira, é capital desenvolver no aluno a aptidão de fruição do texto, para que ele a desenvolva, ao longo de toda a sua vida, em interpretações que contemplem a crescente complexidade das relações sociais.

[...] O texto deve ser visto em seu contexto e não pode ser completamente entendido e interpretado por meio de uma análise de elementos linguísticos [...] Sintaxe, discurso e retórica devem ser integrados à abordagem. (HEMAIS e BIASIRODRIGUES, 2005, p. 110)

Por ser bastante lacônica, a definição do conceito de texto proposta por José Carlos Azeredo cabe vir aqui:

[...] o texto é um produto da atividade discursiva, seja oral, seja escrita. Em um texto circulam, interagem e se integram informações várias, explícitas ou implícitas, ostensivas ou apenas insinuadas. Por isso, um texto tende a ser fruto de uma construção de sentido em que cooperam quem o enuncia e quem o recebe. (AZEREDO, 2008, p. 44)

Uma interessante proposta sobre a articulação do ensino da gramática à realidade do texto se encontra na obra "Aula de Português: encontro e interação", de Irandé Antunes (ANTUNES, 2003).

Nesse livro, a autora trata de questões pedagógicas implicadas no trato docente com a oralidade, a escrita e a leitura de diversos gêneros textuais. Sua tese central é a de que a gramática descontextualizada, isto é, que não demonstre a função, e se restrinja à definição das categorias gramaticais, seria de todo inócua para o aprendizado do aluno.

Como demonstrei, embora considere as articulações de Antunes (2003) imprescindíveis à formação do professor, considero, também, que o ensino da Gramática Padrão como instrumento de lógica e raciocínio, indispensável, até, ao entendimento das demais disciplinas, também deva ocorrer. Na verdade, Antunes (2003) parece ir ao encontro dessa mesma ideia (sobre a necessidade da Gramática como instrumento de desenvolvimento cognitivo), apenas integrando-a, mais uma vez, à tese da indissolubilidade do ensino da Gramática com o do desenvolvimento das habilidades citadas, quando assim se expressa:

Atividades que envolvem operações globais correspondem ao 
v. 6 (2) 292-306 jul/dez 2016 que pesquisas em psicolinguística comprovaram como sendo as mais relevantes, uma vez que a percepção, em qualquer nível, não se realiza por pedaço, mas aos blocos, em unidades integradas (ANTUNES, 2003, p. 122).

Assim, Antunes, no capítulo 3, "Repensando o objeto de ensino de uma aula de português", sintetiza que

Em termos muito gerais, as aulas de português seriam aulas de:

- falar,

- ouvir,

- ler,

- escrever textos em língua portuguesa.

Dentro de uma distribuição e complexidade gradativas, atentando o professor para o desenvolvimento já conseguido pelos alunos no domínio de cada atividade. Mais uma vez, explicito o princípio de que toda atividade linguística é necessariamente textual. Ou seja, a fala, a escuta, a escrita e a leitura de que falo aqui são necessariamente de textos; se não, não é linguagem. (ANTUNES, 2003, p. 111)

Em seguida, Antunes sugere intervenções possíveis que o professor deveria fazer a fim de desenvolver as habilidades aludidas: falar e ouvir; além das competências de escrever e ler. Ela dirá, à frente, com demonstrações de possibilidades de atividades integradoras entre a gramática e a textualidade como acima foi estabelecida, pois "não existe a possibilidade de alguém falar ou escrever sem usar as regras da gramática de sua língua" (ANTUNES, 2003, p 119).

Algumas das sugestões práticas e pedagógicas propostas por Antunes são:

3.1.1 Para o desenvolvimento das habilidades de falar e ouvir, os alunos, com a intervenção do professor, poderiam:

- contar histórias, inventando-as ou reproduzindo-as;

$[\ldots]$

- argumentar (concordando e refutando);

- emitir opiniões;

- justificar ou defender opções tomadas;

- criticar pontos de vista de outros;

Colher e dar informações;

$[\ldots]$

3.1.2 Para o desenvolvimento da competência de escrever, o professor poderia providenciar oportunidades para os alunos produzirem:

- listas (de materiais, de livros, de assuntos, ,,., estudados, de eventos realizados etc.);

$[\ldots]$

- anotações de ideias básicas de textos informativos (a este 
propósito, vale lembrar a vinculação que o professor deve estabelecer entre o português e outras disciplinas);

- pequenas narrativas (criadas ou recriadas a partir de outras, lidas ou ouvidas);

$[\ldots]$

- projetos de pesquisa;

$[\ldots]$

- poemas;

$[\ldots]$

3.1.3 A leitura poderia abranger todos esses textos produzidos pelos alunos, além de:

- histórias, com ou sem gravuras e em quadrinhos;

- fábulas;

- contos;

- crônicas;

- editoriais;

- comentários ou artigos de opinião;

- notícias de jornal;

- poemas;

- avisos;

- folhetos;

- cartazes;

- adivinhas;

- anedotas;

- provérbios populares;

- charadas;

- mapas, tabelas e gráficos;

- anúncios e mensagens publicitárias (ricos no uso de metáforas, metonímias, homonímias, polissemias etc., pelo que se prestam a análises muito interessantes);

[...]

- resumos;

- lições de outras disciplinas etc. (ANTUNES, 2003, p. 111-118)

No fim deste mesmo capítulo, Antunes dá uma série de sugestões de usos (sempre de usos) que podem ser empreendidos pelo professor, a fim de captar as funções das classes e das categorias gramaticais.

Assim, ela aborda o uso dos substantivos como instrumentos referenciais de clareza; o uso de adjetivos ou de locuções adjetivas como elementos que delimitam a referência nominal; o uso dos verbos como elementos sintático-semânticos que selecionam elementos constitutivos dos enunciados, segundo categorias semânticas como as que ela exemplifica com verbos da comunicação verbal (como falar, dizer, comunicar), verbos da atividade psicológica (como pensar, descobrir, refletir, inferir), verbos da percepção (como ver, olhar, escutar, ouvir, perceber), verbos que exprimem movimento (como andar, partir, ir, vir, sair), verbos que exprimem localização (como morar, residir, ficar, viver), verbos que indicam mudança de estado (como tornar-se); o uso de pronomes pessoais, possessivos e demonstrativos como elementos 
V. 6 (2) 292-306 jul/dez 2016

de função referenciadora, de retomadas e antecipações coesivas; o uso dos artigos definidos e indefinidos, como distribuí-los no texto e como isso implica referências ao que já se disse ou a uma informação nova; o uso da concordância verbal e nominal com finalidades expressivas e estilísticas; o uso dos sinais de pontuação como algo relativo ao sentido, à coerência, à compreensão, e o mal uso de alguns sinais como comprometedores do sentido do texto, ao passo que a escolha de outros é de caráter expressivo, enfático.

Pode-se articular esse arrolamento feito por Antunes à obra "Gramática de usos do português", de Maria Helena de Moura Neves. (Neves, 2000). Nessa obra, ao longo de mais de 1000 páginas, a autora trata todos os itens gramaticais, organizados a partir das tradicionais classes morfológicas ou gramaticais, como seu título indica, pelo viés do uso. Assim, na apresentação, Neves orienta que

Para isso, ela [a obra em questão] parte dos próprios itens lexicais e gramaticais da língua e, explicitando o seu uso em textos reais, vai compondo a "gramática" desses itens, isto é, vai mostrando as regras que regem o seu funcionamento em todos os níveis, desde o sintagma até o texto. A meta final, no exame, é buscar os resultados de sentido, partindo do princípio de que é no uso que os diferentes itens assumem seu significado e definem sua função, e de que as entidades da língua têm de ser avaliadas em conformidade com o nível em que ocorrem, definindo-se, afinal, na sua relação com o texto. (NEVES, 2000, p. 13)

\section{Considerações finais}

Este texto não possuiu a pretensão de esgotar o assunto sobre o ensino da Gramática Normativa Padrão da Língua Portuguesa.

No entanto, quis demonstrar alguns impasses, que são de cunho ideológico, epistemológico, teórico, político, didático, pedagógico, e, para além deles, lançar parcimoniosas luzes sobre possíveis soluções a esses entraves.

O que parece emergir de toda a discussão aqui trazida à baila é o fato de que a Gramática Normativa da Língua Portuguesa é uma disciplina fundamental à formação escolar do aluno, e que, para isso ocorrer, é preciso que haja professores capacitados e conscientes de seu papel social.

O ensino de Gramática Normativa deve contar com profissionais de ensino que não desvirtuem sua função: não devem subestimá-la 
à função de meros tutores de comunicação e expressão coloquiais, tampouco é adequado superestimá-la à função de supostos propiciadores da interpretação de todos os códigos existentes. Este último equívoco é frequentemente cometido por professores de outras disciplinas, que, muitas vezes de modo infundado, imputam ao professor de Língua Portuguesa a responsabilidade por todo tipo de falha interpretativa do aluno em outras matérias. É como se o letramento escolar dependesse exclusivamente do professor de Língua, até mesmo no que tange à intelecção e interpretação de aspectos técnicos de outros componentes curriculares.

Reconhecemos que o ensino da Gramática Normativa terá sido eficiente na escola, se tiver ampliado as competências com que o aluno ali ingressou: "digamos que adquirimos a fala, nas suas manifestações espontâneas, na 'escola da vida', mas a escrita, em qualquer de suas manifestações, na 'vida da escola'" (AZEREDO, 2008, p. 66).

O professor de língua que conheça claramente o seu papel, mesmo com todas as dificuldades que se lhe apresentarem, será capaz de conhecer e reconhecer, com precisão, os limites reais da sua responsabilidade sobre a formação do seu aluno.

\section{REFERÊNCIAS}

ANTUNES, Irandé. Aula de Português: encontro e interação. São Paulo: Parábola Editorial, 2003.

AZEREDO, José Carlos. Ensino de português: fundamentos e objetos. Rio de Janeiro: Jorge Zahar Editores, 2008.

BAR-HILLEL, Yeoshua. Pragmatics of natural languages. Londres: Humanitites Press, 1973.

BECHARA, Evanildo. Ensino da Gramática: Opressão? Liberdade? Rio de Janeiro, Ática, 1990.

BENVENISTE, Émile. Problemas de linguística geral. Tradução de Maria da Glória Novak e Luíza Neri. Campinas, Editora da UNICAMP, 1998.

BRAIT, Beth. Análise do discurso e argumentação: o exemplo da ironia. In: MARI, H. (Org.) Fundamentos e dimensões da análise do discurso. Belo Horizonte: Carol Borges-Núcleo de Análise do Discurso. FALE-UFMG, 1999. p. $80-94$.

CAETANO, Marcelo Moraes. Contribuições de Saussure: precursores, paralelos, sucessores e desdobramentos. Revista Confluência, Rio de Janeiro: Instituto de Língua Portuguesa/Liceu Literário Português, n. 50, fev. 2016. Disponível em: <http://llp.bibliopolis.info/confluencia/rc/index.php/rc/article/view/121> Acesso em: 19 de julho de 2016. 
v. 6 (2)

292-306

jul/dez

2016
Desafios da redação. Rio de Janeiro: Editora Ferreira, 2012.

\& CHINI, Alexandre. Nações desenvolvidas e nações evoluídas: o paradigma da Linguística. Instituto dos Magistrados do Brasill. Disponível em: <http://www.imb.org.br/index.asp?pg=Artigos.asp> Acesso em: 20 de julho de 2016.

CHARAUDEAU, Patrick \& MAINGUENEAU, Dominique. Dicionário de análise do discurso. Tradução de Fabiana Komesu. São Paulo: Editora Contexto, 2011.

FIORIN, José Luiz. Intertextualidade e interdiscursividade. In BRAIT, Beth. Bakhtin: outros conceitos-chave. São Paulo: Editora Contexto, 2006. p. 3046.

HEMAIS, B. \& BIASI-RODRIGUES, B. A proposta sócio-retórica de John Swales para o estudo de gêneros textuais. In MEURER, J.L.; BONINI, A.; MOTTAROTH, D. (Orgs.). Gêneros: teorias, métodos e debates. São Paulo: Parábola Editorial, 2005, p. 108-129.

HJELSMELV, Louis. Prolegômenos a uma teoria da linguagem. Tradução de José Teixeira Coelho. São Paulo: Editora Perspectiva, 2001.

MAINGUENEAU, Dominique. Cenas da enunciação. Tradução de Fabiana Komesu. Curitiba: Criar, 2006.

MALINOWSKI, Bronislaw. Uma teoria científica da cultura. Rio de Janeiro: Zahar Editores, 1970.

MARTINET, André. Elementos de linguística geral. Tradução de Jorge MoraisBarbosa. Lisboa: Livraria Sá da Costa Editora, 1973

NEVES, Maria Helena de Moura. Gramática de usos do português. São Paulo: Editora UNESP, 2000.

SCHUCHARDT, Hugo. Brevier. Ein Vademecum der Allgemeinen Sprachwissenchaft. Zusammen gestellt von Leo Spitzer. Halle, 1992.

Recebido em: 19 de jul. de 2016.

Aceito em: 04 de dez. de 2016. 